\title{
La práctica pedagógica en la Licenciatura en Pedagogía Infantil de la Universidad Libre: una mirada desde la sistematización de experiencias ${ }^{1}$
}

\section{The Pedagogical practice of the bachelor in children pedagogy at Universidad Libre: an overview from the systematization of experiences}

\author{
Lucía Nossa Núñez $z^{2}$ \\ lucnossa@hotmail.com \\ Jenny Maritza Pulido González $z^{3}$ \\ jennym.pulidog@unilibrebog.edu.co \\ Nadia Paola Acosta Marroquín 4 \\ paolitaj3@gmail.com
}

Resumen

Este artículo expone la sistematización de las prácticas pedagógicas y sociales en la licenciatura en Pedagogía Infantil Universidad Libre, con miras reconstruir, analizar y reflexionar la experiencia, en la perspectiva de apoyar procesos de revisión curricular al interior del programa académico. Para ello, se propuso una metodología de corte cualitativo, desde un enfoque crítico interpretativo. Como método, se recurre a la sistematización de experiencias. A partir de esto, se encuentran análisis que permiten comprender los sentidos y significados que respecto a la práctica social y pedagógica han construido maestros y estudiantes. Algunas categorías analíticas abordan criterios como concepción de práctica, aspectos que fortalecen la experiencia desde su relación con la investigación y otros espacios académicos, los momentos relevantes por los que han transitado en la práctica los actores educativos y las posibilidades de mejora encontradas en el proceso académico. Para finalizar, se explicita la necesidad de repensar como programa el concepto de práctica social y fortalecer las comprensiones y acciones que respecto a esta se dinamizan, entendiéndola como el eje estructural que soporta la formación de pedagogos infantiles.

Palabras clave: Práctica; Sistematización;Pedagogía infantil, Formación.
This article presents the systematization of pedagogical and social practices in the Bachelor in Children Pedagogy at Universidad Libre, with the purpose of reconstructing, analyzing and reflecting on the experience in the perspective of supporting the academic program curricular revision processes. A qualitative methodology was proposed from a critical interpretative approach. The systematization of experiences was the method used. Based on this, analysis that allow to understand the meanings that teachers and students have built with regarding social and pedagogical practice were found. Some analytical categories deal with criteria such as the conception of practice, aspects that strengthen the experience from the relationship with research and other academic contexts, the relevant moments through which educational actors have gone through in practice and the possibilities for improving found during the academic process. Finally, the needs of the academic program to rethink the concept of social practice and to strengthen the understanding and actions promoted are expressed, understanding practice as the structural axis that supports children teachers training.

Keywords: Practice; Systematization; Children pedagogy; Teachers training.

${ }^{1}$ Artículo de investigación: Sistematización de la práctica en la Licenciatura en Pedagogía Infantil de la Universidad Libre. Código 11040104 y CAP 056 Año 2016.

${ }^{2}$ Licenciada en Pedagogía y Psicología. Docente Universidad Pedagógica Nacional. ORCID https://orcid.org/0000-0002-8724-052X

${ }^{3} \mathrm{Mg}$. en Educación. Docente catedrática en la Universidad Libre de Bogotá. ORCID https://orcid.org/0000-0003-1034-300X

${ }^{4} \mathrm{Mg}$. en Investigación Social Interdisciplinaria. Docente tiempo completo en la Universidad Libre de Bogotá. ORCID https://orcid.org/0000-0002-3529-4075

*Cómo citar este artículo: Nossa, L., Pulido, J. \& Acosta, N. (2018). La práctica pedagógica en la Licenciatura en Pedagogía Infantil de la Universidad Libre. Hojas y Hablas, (15), 116-131. DOI: 10.29151/hojasyhablasn.15a7 


\section{Introducción}

La práctica pedagógica en la Licenciatura en Pedagogía Infantil de la Universidad Libre, en adelante Unilibre, se concibe como un eje transversal para la formación de las estudiantes que se desarrolla desde II hasta IX semestre. El ejercicio de los primeros cinco semestres se denomina práctica social; el trabajo de séptimo a noveno semestre recibe el nombre de práctica docente e investigativa.

La práctica constituye la posibilidad reflexionar, interpelar y transformar los diferentes entornos en donde interactúan las estudiantes y consolidar su formación por medio de experiencias docentes en el aula. Para ello, la licenciatura ha gestionado la posibilidad de contar con diversos escenarios educativos, con la firma de convenios en instituciones que trabajan con niños y niñas de 0 a 7 años de edad y ha desplegado diferentes acciones pedagógicas que apoyan los procesos dinamizados al interior de las prácticas.

Con relación a lo anterior, se asume la práctica como un escenario ineludible para la profesión docente, tanto para la comprensión del quehacer pedagógico como para los desarrollos académicos de la pedagogía. Como un ejercicio reflexivo, que permite comprender los sentidos del proceso o de los actos educativos, cobrando gran importancia la labor de las maestras en formación, como profesionales que pueden incidir en las transformaciones de distintos escenarios en donde hace presencia la infancia.

Así, para la licenciatura en Pedagogía Infantil,

"La práctica pedagógica se inscribe como posibilidad de construcción, reconstrucción y deconstrucción permanente de sentidos y significados que configuran el espectro amplio del hecho social educativo y lo problematizan a través de la investigación. La práctica se entiende como escenario formativo desde el cual se interpelan diversas imágenes y concepciones frente a infancia, maestro, educación, pedagogía y didáctica" (Licenciatura en Pedagogía Infantil, documento de condiciones iniciales, 2015, p. 6).

\section{La importancia de sistematizar la práctica peda- gógica en el programa de Pedagogía Infantil}

En primera instancia, es necesario indicar que el concepto práctica es de carácter polisémico por cuanto recoge la multiplicidad de construcciones que emergen en diversos contextos y hace referencia a procesos de transmisión cultural que se realizan conforme los ideales de un escenario particular. En esta medida, las prácticas constituyen la realidad y a su vez la configuran; ello implica una relación bidireccional, constante, complementaria y dinámica en la cual entran en juego condiciones, deseos, intereses, saberes de las personas.

Ahora bien, entendiendo que el ejercicio de trabajo pedagógico que realizan las estudiantes de la licenciatura de segundo a sexto semestre se denomina práctica social, es fundamental entender que asumir esta categoría implica tener en cuenta la posición de los agentes, sus trayectorias, relaciones y propósitos en determinados escenarios (Bourdieu, 2007). Se requiere también comprender su carácter dinámico y heterogéneo que desencadenan en múltiples dinámicas. Como lo indican Castro et al (1996), las prácticas sociales pueden pertenecer a tres esferas: socio- parentales, socio- económicas y socio-políticas. Es en esta última donde se ubican las prácticas pedagógicas.

Estas, según Zuluaga (como se citó en Runge, 2002), estructuran un espacio en el cual confluye el saber disciplinar y la acción social, constituido por la acción en sí misma, libre y reflexionada (Runge 
y Muñoz, 2012). En dicho espacio, se reflexiona, se interpreta y se construye alrededor de los propósitos de la educación, de las vías empleadas para la producción del saber, de los discursos circulantes y de los dispositivos que permean las instituciones, a lo cual se espera acercar a las estudiantes de la licenciatura durante los últimos semestres de formación académica.

Allí, concurren conocimientos teóricos, prácticos, que se ponen en acción a partir de diversas estrategias tanto para los procesos de enseñanza, como de aprendizaje. A partir de la experiencia de la práctica se explicita la relación maestro-conocimiento-alumno, el enseñar y el aprender se resignifica a partir de procesos reflexivos con el estudiante (Duhalde, 2007).

Para Díaz (2006), la práctica pedagógica y el saber pedagógico, se constituyen en dos categorías relevantes para la formación docente, desde donde es posible develar el carácter ontológico, teórico y epistemológico de la misma; de esta manera, recurrir a la reflexión misma de la práctica es también hacer visible, procesos de la formación misma como maestras.

Por su parte, la sistematización se relaciona con la comprensión de acciones desarrolladas en el marco de la práctica pedagógica por parte de los estudiantes y maestros la licenciatura y con los significados que han construido. En consecuencia, tiene que ver con lo que se hace, con los procesos involucrados, con las intencionalidades expresadas. Así, sistematizar implica explicitar las razones o motivos de las acciones y finalidades que se persiguen, para comprender $y$ transformar los procesos llevados a cabo.

En este contexto se plantea la pregunta
¿Cuáles son los sentidos y significados que docentes y estudiantes del programa de Pedagogía Infantil de la Universidad Libre de Colombia han construido en relación con la práctica social y la práctica investigativa?

A partir de este cuestionamiento, se plantea como propósito general reconstruir la experiencia de la práctica social y pedagógica investigativa, durante los años 2004 y 2015, con miras a develar los sentidos y significados que docentes estudiantes han construido en torno a esta en la licenciatura en Pedagogía Infantil, Universidad Libre.

Como puede observarse, se encuentra en este trabajo de sistematización una oportunidad para comprender críticamente los tránsitos de la práctica pedagógica y a su vez entrever lógicas que permean la misma.

Es importante advertir que, para este programa académico, la práctica se considera como escenario formativo en el cual se aprende con el otro respecto a las complejidades del ser maestro de niños y niñas, además, se interpelan diversas imágenes y concepciones frente a maestro, infancia, juventud, educación, pedagogía, didáctica, entre otros. Allí emergen interrogantes que tensionan estos y las relaciones que mantienen entre sí, a fin de encontrar nuevos horizontes de conocimiento. La práctica se convierte entonces en lugar que enriquece, valida y confronta la formación profesional, permite incidir en diversos contextos que exigen de la educación, nuevas miradas, otros aportes, distintas alternativas de transformación.

Por su parte, la práctica docente investigativa se asume como un escenario de problematización, de diálogo, de encuentros y desencuentros en diversos contextos y con diferentes infancias y maestros (Licenciatura en Pedagogía Infantil, 
documento de condiciones iniciales, 2015). La Práctica Pedagógica Investigativa (PPI) denominada en la malla curricular Proyecto Investigativo y Práctica Docente I, II y III, se inicia desde séptimo semestre y está articulada con el desarrollo del proyecto de investigación que se debe socializar en noveno semestre dentro de un proceso de investigación formativa conducente a innovaciones pedagógicas y didácticas en el contexto de la práctica.

\section{Ruta metodológica: ¿Cómo entender la sistema- tización de experiencias?}

El enfoque metodológico asumido es la sistematización de experiencias, la cual se sitúa en el paradigma cualitativo, enfoque crítico social en tanto encuentra en la reconstrucción histórica de determinadas experiencias, una posibilidad de transformación social y recontextualización de saberes, para Jara (2014) se trata de combinar la reflexión teórica y las experiencias vividas con las herramientas y propuestas para la práctica.

Es importante precisar que el concepto de sistematización de experiencias proviene del trabajo social, de la educación de adultos y del trabajo comunitario. Campo donde se destaca la posibilidad de aprender de las prácticas cotidianas, de las experiencias vividas, de las intervenciones espontáneas en la realidad por parte de personas comunes o no expertas. No obstante, su uso se ha ido ampliando hasta considerarlo como un modo de producción de conocimientos (Carvajal, 2004) o una modalidad de investigación social. Según Jara (2001), "se trata de mirar las experiencias como procesos históricos, procesos complejos en los que intervienen diversos actores, que se realizan en un contexto económico-social determinado y en un momento institucional del cual formamos parte" (p.1). Así, que experiencia de práctica se puede entender como un proceso histórico, propuesto por un equipo de maestros que, en el marco de la formación de pedagogos infantiles, entienden la necesidad de propiciar escenarios educativos en donde sea posible la reflexión pedagógica.

Desde este punto de vista, la sistematización "explicita, nombra, contextualiza y fundamenta diversos saberes, competencias prácticas, aprendizajes, lecciones aprendidas que la experiencia acumula en los sujetos que la desarrollan" (Escobar y Ramírez, 2010, p.101).

Al respecto, Alfredo Ghiso (1998), expone algunas características de la sistematización, en donde propone que, a todo proceso le antecede una práctica susceptible de ser recuperada, resignificada, reconstruida a partir del proceso investigativo. Allí, la acción y el saber de las personas frente a su acción, son aspectos esenciales para toda sistematización, de ahí que la voz de las maestras y estudiantes como principales actores del proceso orientan la reconstrucción de la experiencia.

En consecuencia, la sistematización conlleva un proceso permanente de diálogo entre los sujetos, en el cual, los encuentros y desencuentros hacen parte de la experiencia misma. Siguiendo a Suárez (2011), la narración de la experiencia educativa puede entenderse como una estrategia de trabajo que orienta la coindagación de prácticas e interpretaciones pedagógicas de las personas partícipes de la misma.

En la misma lógica, Torres (1999), destaca la sistematización como una producción intencionada de conocimientos, es decir que no es producto de la espontaneidad, sino que- por el contrariose sitúa en un nivel epistemológico, teniendo en cuenta desde dónde, para qué y cómo se producen los conocimientos, saliendo de lugares acríticos. 
Esta producción colectiva de conocimientos, reconoce y se compromete en hacer sujetos de conocimiento a los actores de la sistematización, quienes a la vez toman las propias decisiones de transformación del proceso.

Por su parte, García y Tirado (2010), sostienen que "la sistematización no se refiere a cualquier acción, sino a la que tiene lugar en el marco de proyectos y programas de desarrollo, es decir, de intervenciones intencionadas, con objetivos de transformación de la realidad” (p.100). Desde esta postura, se reconoce la práctica pedagógica como producto de un contexto especifico, con elementos y actores particulares que constituyen la experiencia.

En este orden de ideas, la sistematización de experiencias se entiende, por parte del equipo investigador, como posibilidad de construcción colectiva de saberes y conocimientos contenidos en las prácticas sociales, en la que, a partir de un proceso de ordenamiento, reflexión, evaluación, análisis e interpretación de la experiencia, es posible orientar nuevas prácticas y aproximarse a la producción de conocimiento. En el marco de este ejercicio investigativo, la apuesta es por reconstruir e interpretar las experiencias que en el ámbito de la práctica se han desarrollado en la Licenciatura en Pedagogía Infantil de la Universidad Libre.

Bajo esta perspectiva, se establecieron siete momentos para el diseño, puesta en marcha e interpretación del proceso, a decir:

- Problematización inicial: definición del objeto de estudio de cara a las necesidades de la licenciatura en términos de volver interpretativamente sobre la experiencia de práctica social y docente investigativa.
-Definición de categorías deductivas: estructuradas a partir de las preguntas iniciales de investigación, como lo fueron, ¿qué concepciones de práctica circulan en estudiantes y maestros de la licenciatura?, ¿qué significados otorgan estos actores al proceso de práctica del cual han sido partícipes? ¿qué transformaciones se han presentado durante el periodo comprendido entre el año 2004 a 2015 en la práctica social y docente investigativa en la Licenciatura en Pedagogía Infantil de Unilibre?, ¿qué momentos relevantes pueden identificarse a partir de la reconstrucción de la experiencia?

-Levantamiento de la información: realización de cuatro grupos focales (dos con estudiantes y dos con maestros de la licenciatura), realización de entrevistas a partir de las categorías deductivas:

* Propósitos de la práctica

* Concepciones de práctica

* Momentos relevantes del proceso

- Transcripción y decodificación alfanumérica de lo relatado en los grupos focales y entrevistas, para posteriormente organizar los párrafos en criterios temáticos (a cada maestro se le asignó un número y se le identificó con la letra D; así mismo se procedió con los estudiantes a quienes se les asignó la letra E). A propósito de esto, es importante mencionar que, para el equipo de investigación, los relatos de los autores se constituyen en ruta principal para la comprensión de la experiencia, pues, como lo señala Messina y Osorio (2016), "la sistematización es en el relato, habita en él como se vive en la casa familiar, en confianza y también con una cierta incomodidad, con ganas de salir, de aventurar hacia otros lugares" (p.606).

- Construcción de una matriz analítica de lo encontrado en los documentos oficiales de la licenciatura a partir de las categorías deductivas. En 
esta revisión se buscó ubicar el sentido que para el programa académico tiene la práctica social y docente investigativa.

-Organización de la información que emergió de las entrevistas, grupos focales y revisión documental a partir de categorías deductivas:

* Propósitos de la práctica

-La práctica como lugar de experimentación

-La práctica como espacio de confrontación teórica

-La práctica como el lugar para el reconocimiento de contextos.

-La práctica como proceso de formación

*Concepciones de práctica:

-Espacio para evidenciar los conocimientos

-Eje transversal en la formación

-Escenario de reflexión

${ }^{\star}$ Momentos relevantes del proceso

-Las primeras experiencias

-Las tensiones: del qué hacia el por qué

-Un nuevo puente vinculante: práctica e investigación

-Análisis.

-Elaboración del informe final.

\section{Resultados del proceso vivido}

En el transcurso de la investigación, se hizo evidente que diversos son los lugares desde los que se han asumido las experiencias construidas a partir de la práctica y distintos los escenarios desde los cuales es susceptible analizar la misma. En este contexto, cobró especial interés reconocer los tránsitos que se han configurado en relación con las concepciones de práctica, justamente, por encontrar en la voz de los actores, maestros y estudiantes que han venido elaborando significados respecto a la misma.

\section{Propósitos de la práctica}

Frente a este panorama, emerge una aproximación inicial en cuanto a los propósitos de la práctica por parte de las estudiantes de diferentes semestres de la Licenciatura; estos enunciados permiten develar la idea de cómo las maestras en formación entienden la finalidad de la práctica:

La práctica como lugar de experimentación. Los estudiantes expresan que la práctica se direcciona a potenciar un "espacio de aprendizaje, reflexión, construcción de saberes en se puede experimentar la teoría y verificar de manera individual la realidad educativa que vivencia nuestro país” (E3). Aquí se recalca el lugar preponderante de la práctica como espacio para conocer, de primera mano, las dinámicas del aula, las distintas maneras de ser niños y niñas, y desde luego, las distintas formas de actuar y ser maestro de educación infantil, comprendiendo así el mundo escolar en el escenario nacional (Suárez, 2011). La experimentación se instala entonces como posibilidad de acción y puesta en marcha de múltiples alternativas de trabajo con y para la infancia que preparan a los estudiantes para asumir grupos de trabajo que demandaran de ellas un despliegue creativo y propositivo, para ser consecuente con uno de los propósitos de la práctica social de la Licenciatura en Pedagogía Infantil “incorporar al futuro/a pedagogo/a infantil en el ejercicio docente, permitiéndole aplicar los conocimientos aprendidos a la solución de problemas propios de su campo y reflexionar sobre su experiencia” (Universidad Libre, 2005, p.54).

De lo anterior, puede inferirse que la práctica se convierte en un espacio para acercarse a las experiencias, la cual "ayuda a la formación y a la experimentación de nuevas vivencias" (E1), 
que posteriormente han de permear el ejercicio docente y siendo ello así, el presente de la misma: las complejidades que depara el día a día, serían la oportunidad para intentar conjurar un futuro que, aunque incierto, ya ha dado atisbos de comprensión.

\section{La práctica como espacio de confrontación}

teórica. Para algunos estudiantes y maestros, el diálogo con los desarrollos teóricos que se trabajan en la Licenciatura y las experiencias de la práctica se convierten en eje estructurador de la misma. Sostienen que la contrastación permanente que se establezca entre teoría y práctica es sustancial para el trabajo pedagógico con la infancia, pues es este el lugar desde el cual se lee la cotidianidad del trabajo con niños y niñas. Al respecto un profesor señala que, "es un espacio propicio para el maestro en formación, para preguntarse por su hacer, indagar, asombrarse, contrastar la teoría con su hacer, es decir, reflexionar para a partir de allí posibilitar nuevas formas de construcción" (D3).

$\mathrm{Al}$ respecto es importante aclarar que la práctica pedagógica se constituye a partir de "currículo teóricos y prácticos como elementos que fundamentan la misma. El primero surge como el resultado de un proceso de construcción del discurso, es de carácter reflexivo (...). El currículo práctico hace referencia específica a los procesos de enseñanza y aprendizaje que se desarrollan en el proceso interactivo entre el profesor y estudiante" (Alvarado, 2013).

Así, emerge la necesidad por comprender la práctica desde su carácter complejo y procesual en la que generalmente, el orden, el seguimiento juicioso de eslabones, la linealidad, suele fisurarse frente a la situación que desconcierta, interroga y demanda nuevas aproximaciones y búsquedas. Entonces, es este escenario un "eje transversal en la formación de todo licenciado, permitiendo y promoviendo la reflexión permanente desde lo teórico para ser desarrollado en la práxis, desde una postura crítica" (D5).

\section{La práctica como lugar para el reconoci-} miento de contextos. Acercarse a la comprensión de las diversas realidades que se construyen con las distintas infancias en contextos variados, es uno de los fuertes potenciales que se le atribuye a la práctica en la Licenciatura. "La experiencia de la práctica ha transformado mi vida, permitiéndome tener un acercamiento real a la primera infancia; he podido llevar mis conocimientos al campo real de acción, dándome la satisfacción de ver los resultados en los procesos de los niños" (E5). Que las maestras en formación interactúen con personas y ambientes cambiantes, fortalece su proceso de formación en la perspectiva de interrogar el lugar predominantemente andro y eurocéntrico desde el cual se legitimaban muchos de los discursos que circunscriben maneras determinadas de pensar en niños y niñas. Es pues "un espacio en el cual las docentes en formación tenemos la oportunidad de un primer acercamiento con la infancia en distinto espacios" (E5).

Es justamente en el reconocimiento de los contextos, en dónde comienzan a elaborarse comprensiones del ser maestro en escenarios amplios y retadores.

La práctica como proceso de formación. Se instala en esta perspectiva la mirada de la práctica como dinámica inherente a la formación docente propiciadora de la multiplicidad de experiencias que fortalecen la re-conceptualización y re-contextualización de los saberes y conocimientos trabajados en el transcurso de su vida universitaria. "Es un espacio de acción-participación y formación donde se hace visible lo aprendido en los ejes 
temáticos y en donde se da la oportunidad para enfrentarnos a la realidad del ser pedagogo infantil" (E2).

La práctica se configura, desde esta perspectiva, en eje transversal que delimita el lugar de la pedagogía infantil, del maestro en educación inicial, de las didácticas, las propuestas metodológicas, la cotidianidad del trabajo con niños y niñas en el aula, y desde luego, en escenarios no escolarizados, cuando las particularidades mismas de las prácticas dan vía libre a esta alternativa. No obstante, a este respecto, resultan imperativos mayores desarrollos que revistan la práctica en estos escenarios de un fuerte sustento que legitime la presencia de un pedagogo infantil allí, de modo que se potencie el "reconocer las infancias en sus diferentes desarrollos, contextos relacionarse directamente con su objeto de estudio. Ir formándose a partir de posturas epistémicas claras" (M2).

\section{Concepciones de práctica, por parte de los actores (estudiantes y docentes)}

$\mathrm{Al}$ indagar en relación con lo que los maestros del programa consideran puede definirse como práctica pedagógica, emergen respuestas que la instalan en dos perspectivas interpretativas.

Por una parte, algunos docentes expresan que la práctica es un "espacio que tienen los estudiantes para poner en evidencia sus conocimientos, enfrentándose a la realidad de su quehacer docente" (D4). Desde este punto de vista, la práctica podría asumirse como lugar que es susceptible de descubrir los aprendizajes de los estudiantes a través de la puesta en escena de su acervo académico, lo cual, de facto, les permite también, afrontar las condiciones propias del acto educativo institucionalizado. En este contexto, la práctica es un medio para evidenciar algunas de las comprensiones de su vida académica y también, para, asumir las complejidades de su quehacer.

En segunda instancia, se devela la idea de práctica como "eje transversal en la formación de todo licenciado, permitiendo y promoviendo la reflexión permanente desde lo teórico para ser desarrollado en la praxis, desde una postura crítica" (D2). Aquí, la práctica transitaría del lugar de medio, hacia el de eje transversal, o mejor aún, elemento sustancial a la formación docente en el cual se reflexionaría a partir de la teoría, postura que desde importantes desarrollos, podría ser altamente problematizada si se tiene en cuenta, entre otras cosas, que el saber pedagógico es gran medida un saber práctico y entonces, suponer que se reflexiona exclusivamente desde la teoría, implicaría desdibujar los saberes que a partir de y en la experiencia se construyen y han incidido en la producción de conocimiento. "Escenario de reflexión y apropiación del sentir pedagógico que requiere todo maestro para fortalecer su quehacer" (D2).

Emerge también la idea de la práctica como escenario, lo cual llevaría consigo el asumir cada encuentro pedagógico como un espacio para la actuación, para la exposición y, recogiendo los postulados de Larrosa (2014), solo desde esta exposición es posible la experiencia. Entender la práctica como escenario conlleva a pensarla como dinámica, capaz de transformarse y de transformar a las personas. La idea de la práctica como escenario ofrece metáforas importantes para el análisis, como lo es la preparación de un acto, la comprensión de quiénes son los espectadores, cuál es el contexto de actuación. En fin, es evidente que una idea así moviliza y, en consecuencia, se distancia de la reproducción de actividades naturalizadas y por qué no decirlo, improvisadas, pues, insistiendo en la metáfora del escenario, quien improvisa en este es quién ha construido un saber y una experiencia durante un amplio periodo. 
Ahora bien, el concepto sentir pedagógico obligaría a considerar el lugar que ocuparían las emociones en la práctica y si estas, efectivamente, son exógenas, se producen en el afuera del sujeto, pues, al definirlas como aquello que se apropia, podría pensarse en lo existente que se internaliza en la perspectiva de fortalecer el quehacer docente. Ante ello, el interrogante ¿qué emociones circulan en el espacio escolar en el cual me desenvuelvo y cómo las asimilo?, suscitaría un fuerte debate. Quizá sea oportuno pensar también en cómo el sentir propio interpela el contexto de actuación.

Además de lo acotado, cobra especial relevancia enfatizar en la idea de la práctica como un espacio propicio para el maestro en formación, pues, desde este punto de vista podría afirmarse que el maestro en ejercicio (si se quiere, quien posee un título) ya no transitaría por la práctica pedagógica y entonces, este sería un saber que se construiría exclusivamente durante el proceso de formación universitaria. Esta idea se instala fuertemente en las enunciaciones cotidianas de muchos docentes y subyace en esta la mirada de un proceso anclado en el tiempo.

El lugar de la reflexión resulta también preponderante, en tanto se ubica aquí una fuerte posibilidad de transformación vía asombro y contrastación de la teoría con su quehacer. Al respecto, es importante advertir que, siguiendo a Jara (2012), cuando se habla de transformación, se hace alusión a un proceso realizado por personas "con capacidad de construir conocimiento crítico, vinculado a los dilemas de una práctica social y a los saberes que ella produce $y$, que, por tanto, desarrollan -como un componente de la propia práctica- la capacidad de impulsar y pensar acciones transformadoras" (p.59). De esta forma, la práctica cobraría sentido en la medida en que las reflexiones producto de la misma movilizaran dinámicas que interrogasen por el acto educativo que allí tiene lugar.

Así pues, es posible visibilizar la variedad de concepciones que en relación con la práctica han construido los docentes del programa, las cuales han de ponerse en diálogo en la perspectiva de ubicar puntos que nucleen el acompañamiento que se hace en las instituciones y desde luego, de la formación de los pedagogos infantiles.

Ahora bien, en términos del tiempo de experiencia como asesores de práctica, hay un promedio de seis años por docente, espacio importante para reelaboraciones, conceptualizaciones y procesos de consolidación, no solo frente a la formación de las estudiantes de la licenciatura, sino también, al fortalecimiento mismo de la estructura curricular del programa de cara a la lectura y el análisis de textos y contextos, asunto que valdría la pena revisar en términos de consolidar equipos de diálogo que atiendan analíticamente a asuntos nodales de la formación de pedagogos infantiles.

\section{Momentos relevantes del proceso}

Con el objeto de conocer, cómo para los maestros del programa ha ido transformándose el proceso de la práctica pedagógica a través de la experiencia de la Licenciatura, se indagó por los cambios que el equipo considera, han sido importantes y relevantes durante los últimos años. En este contexto, se ubica el proceso de acreditación como un momento sustancial para la dinamización de reestructuraciones "de la propuesta de práctica del programa" (D1), el cual ha demando un trabajo interdisciplinar que permita consolidar la formación de las estudiantes y a su vez, delimitar líneas de investigación que fortalezcan, precisamente, la investigación en el marco de la licenciatura. En este contexto se ubica la urgente 
necesidad de "asignar créditos académicos a la práctica de primero a sexto semestre" (D3), ello en tanto la no formalización en el plan de estudios resta importancia de la misma y en consecuencia, el compromiso de algunas estudiantes frente a este espacio.

Otro momento clave en el proceso de transformación de la práctica se inscribe en el cambio de la directora del programa, desde el cual "se ha potenciado el trabajo colaborativo con los asesores del programa" (D4) y a su vez, la apertura a nuevas propuestas e iniciativas por parte de los maestros de la licenciatura. Como consecuencia de esto, se destaca "el fortalecimiento en la formación de las estudiantes a partir del acompañamiento, el diálogo y la lectura de sus escritos" (D3).

Ello ha incidido en un "mayor énfasis y cristalización del sentido de la práctica en cada semestre, así como en la posibilidad de nuevos convenios con otros espacios, mayores recursos materiales y bibliográficos para el trabajo en la práctica” (D5).

En este orden de ideas, se resaltan también como momentos importantes, el avance significativo que ha tenido la práctica en el segundo semestre, en el cual, se "ha potenciado un ejercicio escritural a través de los registros en los diarios de campo" (D2); este es un insumo fundamental para el trabajo en tercer semestre y en consecuencia, se constituye en una apuesta de integración curricular. Así mismo, se espera que, en los semestres en mención, los estudiantes "logren identificar la concepción de infancia en el contexto de su sitio de práctica" (D1).

Además, se resalta la propuesta de práctica en sexto semestre, en el cual se organiza el trabajo a partir de un tema específico, a decir, lectura y escritura, ello valiéndose de los contenidos abordados en el eje temático de lengua materna. $\mathrm{Al}$ respecto se destaca también el trabajo dinamizado en el espacio académico de literatura infantil, en el cual se buscan articulaciones con los diferentes escenarios de práctica.

En el panorama expuesto, maestros de la licenciatura expresan la transformación de la práctica desde la reflexión, cualificación y experticia durante los últimos años, así como vislumbrar en algunos estudiantes la valoración de ser maestros y su práctica como un momento de gran responsabilidad y compromiso (D4).

En cuanto a obstáculos que se han percibido en el proceso de práctica pedagógica, se señala no contar con el apoyo económico para el desplazamiento a los diferentes escenarios de práctica pedagógica; el que la práctica de segundo a sexto semestre no se encuentre registrada en el Sistema Institucional de la Universidad Libre (SIUL) y, en consecuencia, no haya "asignación para la misma y los tiempos de acompañamiento se cuentan cómo horas de permanencia" (D3). Para el caso del proyecto investigativo y la práctica docente, sobresale como dificultad "el tener demasiados proyectos de investigación” (D1), asunto que además de incidir en una dispersión temática que se escapa en ocasiones a las posibilidades de acompañamiento de los maestros, también "desgasta" (D3).

A su vez, como fortalezas se resalta el "trabajo colaborativo entre los docentes del programa; los nuevos espacios en dónde se está desarrollando la práctica y el mayor compromiso que se evidencia en las estudiantes en cuanto a las lecturas, planeaciones y asistencias a sitios de práctica; la intencionalidad por fortalecer la práctica y darle un sentido; el sentido de pertenencia por el programa. La responsabilidad, el respeto hacia la infancia" (D5). 
Frente al panorama expuesto, se advierten los importantes esfuerzos por parte del equipo de la licenciatura a fin de fortalecer la formación de las estudiantes y desde allí, proyectar el programa en diferentes escenarios escolares, familiares, científicos, comunitarios y que responden a la necesidad de ampliar los horizontes de acción, comprensión e investigación de los pedagogos infantiles, frente a lo cual, los desarrollos en este espacio son fundamentales.

En relación con los momentos significativos en el transitar de la práctica y a partir de los hallazgos de la investigación, es posible evidenciar momentos claves por los cuales han transitado las prácticas en la licenciatura en Pedagogía Infantil de la Universidad Libre, los cuales hablan no solo del significativo avance en términos de cualificación de los procesos académicos, sino también de las oportunidades que desde diversos lugares emergen para repensar el lugar de las prácticas en la formación de maestros. En este sentido, han logrado ubicarse tres momentos que se constituyen en puntos claves de análisis frente al devenir de este ámbito de formación, a decir:

\section{Las primeras experiencias: un camino en construcción}

En los inicios de la licenciatura, año 2004, los acercamientos de los estudiantes a los escenarios de práctica podrían considerarse embrionarios. La claridad por parte de los maestros de ese entonces frente al lugar preponderante de la práctica en la formación de pedagogos infantiles, no se revertía en rutas metodológicas concretas que permitiesen puntualizar dicho precepto. Como es apenas lógico, el camino estaba por construirse y entonces, la práctica social que ya desde hace varios semestres se adelantaba en las otras licenciaturas de la Facultad de Ciencias de la Educación, se constituyó en referente y posibilidad para, por una parte, acercar a los estudiantes a distintos contextos educativos, y a su vez, preparar los aspectos necesarios ante el trabajo que comenzaría en séptimo semestre con el proyecto investigativo y la práctica docente, el cual demandaría de mayores elaboraciones y además, ubicación de escenarios que permitiesen la construcción de proyectos de grado.

En este marco, la experiencia comienza, como es apenas natural, con muchas dificultades: desde el escaso número de maestros para acompañar a los estudiantes, no solo en los contextos de práctica sino también en la asesoría a sus trabajos de grado, hasta la urgente necesidad por ubicar líneas de discusión que permitiesen configurar un derrotero hacia el cual orientar el trabajo de los maestros y los estudiantes. En este contexto, es posible afirmar que la práctica desarrollada por los estudiantes en sus inicios, se caracterizaba fuertemente por el interés preponderante para que niños y niñas estuviesen ocupados, en el entendido que ello denotaría mayor dominio de grupo por parte del maestro en formación. Para tal efecto, resultaba necesario que el estudiante no perdiese de vista los objetivos que buscaba lograr con la actividad propuesta, pues, se constituían estos en los referentes de acción y evaluación de la misma, lo cual, vale la pena decirlo, dejaba a un lado los procesos reflexivos que orientaría la construcción de los sentidos de las diferentes acciones pedagógicas.

Indudablemente este es el resultado no solo de los procesos de acompañamiento de los maestros (quienes, por las condiciones ya expresadas, no contaban con los tiempos requeridos para el trabajo en los diferentes escenarios de práctica), sino también de las vivencias escolares particulares que permeaban fuertemente los procesos de interacción con niños y niñas e incidían en las maneras de entender y asumir el trabajo pedagógico, 
como por ejemplo, el considerar que para aprender es necesario un mismo ritmo de aprendizaje para todo el grupo e incluso, suponer que todos han de aprender lo mismo. Así, la práctica se ve subordinada a normas y reglas que devienen del afuera de la experiencia pedagógica y, aun así, ejercen una fuerte influencia en los procesos de formación de los pedagogos infantiles.

Sin embargo, para algunos maestros, comienza a emerger una "transformación desde la reflexión, cualificación y experticia durante los últimos años en la práctica, se percibe en algunos estudiantes la valoración de ser maestros y su práctica como un momento de gran responsabilidad y compromiso" (D2).

Esto se constituyó también en punto de partida para visibilizar la necesidad apremiante de pensar el proceso de formación de los pedagogos infantiles a partir del camino recorrido hasta el momento. "Los nuevos espacios en dónde se está desarrollando la práctica y el mayor compromiso que se evidencia en las estudiantes en cuanto a las lecturas, planeaciones y asistencias a sitios de práctica; la intencionalidad al interior del programa por fortalecer la práctica y darle un sentido; la responsabilidad, el respeto hacia la infancia” (D1)

\section{Las tensiones: del qué hacia el por qué}

Conforme se avanza en la experiencia de la práctica social y el proyecto investigativo, mayores son los elementos que permiten identificar lo preponderante que resultaba el hecho de discutir su lugar en la formación de los pedagogos infantiles, de manera especial, cuando comenzaba a percibirse una tendencia hacia el activismo, en la cual, la práctica se constituía en escenario privilegiado para aplicar lo visto en los diferentes ejes temáticos, de manera tal que su sentido se construía a partir de los desarrollos de otros ámbitos académicos.

Este panorama incidió en que resultase necesario, desde el campo de práctica, dinamizar discusiones que llevaran a profundizar sobre el quehacer de las estudiantes en sus diferentes escenarios de intervención y a su vez, por el acompañamiento que recibían por parte de los maestros, en la perspectiva de ubicar fortalezas y dificultades tanto en las diferentes instituciones, como en los procesos de acompañamiento de los maestros de la universidad, ello en tanto era evidente en algunos casos, cómo la formación disciplinar se convertía en referente central para pensar en los procesos pedagógicos con niños y niñas, inadvirtiendo que las particularidades y complejidades de la pedagogía infantil se sitúan en lugares de enunciación interdisciplinar y a partir de saberes situados.

El concepto de aprendizaje significativo comienza a integrar muchas de las propuestas que los maestros direccionan frente al trabajo con sus estudiantes. Aquí, las didácticas específicas se convierten en asidero teórico para sustentar y pensar muchas oportunidades de intervención pedagógica con niños y niñas, que, a su vez, empiezan a distanciarse de la perspectiva aplicacionista referida antes. La práctica permite también fortalecer la mirada de los niños como sujetos activos y propositivos.

A propósito de ello, resulta también necesario insistir en el maestro titular de las instituciones de práctica como referente fundamental para la comprensión del estudiante frente al quehacer pedagógico en educación infantil, por lo cual, la interacción se convierte en un aspecto sustancial. 
Es importante incluir la relación de diálogo y colaboración con los tutores de centros: asumir el valor de aumentar y mejorar la comunicación entre los contextos escolares y la universidad, por tanto, crear un espacio para el aprendizaje, negociar objetivos y diseñar estrategias conjuntamente con el propósito de construir significados compartidos sobre el proceso reflexivo de las prácticas (Hamel y Ryken, 2010, p.35).

\section{Un nuevo puente vinculante: práctica e investigación}

Indudablemente, uno de los cambios (pausado pero importante) que se ha suscitado en el sentido de práctica del programa de Licenciatura en Pedagogía Infantil de la Universidad Libre, es el referido a la influencia del pensamiento Freireano en el proceso de formación de pedagogos infantiles, caracterizado por la indagación, acción y puesta en marcha de propuestas transformadoras que generen espacios reales de diálogo y confrontación con los sujetos, con los contextos. Ello ha impulsado que los escenarios de práctica sean más amplios y diversos, en los cuales los estudiantes no solo se ven enfrentados a problemas didácticos, sino también socio políticos que demandan su posicionamiento crítico frente a los acontecimientos de las comunidades y el lugar del maestro en los mismos.

Justamente en este panorama, la investigación se instala como oportunidad para la lectura de textos y contextos que permitan acercarse a la comprensión de diferentes fenómenos educativos y pedagógicos y en muchos casos, construir propuestas de acompañamiento en las instituciones de práctica. "Han existido muchas relaciones de la práctica con la investigación, ya que surgen muchas incógnitas al ir a la práctica y que de una $\mathrm{u}$ otra forma podemos llevarlas a un tema de investigación" (E3)
Siendo ello así, la práctica comienza a inscribirse como posibilidad para la construcción de saberes y la comprensión del rol del maestro de pedagogía infantil. Se entiende como escenario formativo desde el cual se interpelan diversas imágenes y concepciones frente a infancia, juventud, educación, pedagogía, didáctica. La práctica se convierte entonces en lugar que enriquece, valida y confronta las construcciones teóricas, a partir de lo cual, incide en los diversos contextos que exigen de la educación, nuevas miradas, otros aportes, distintas alternativas de transformación y es también el escenario privilegiado para aprender de los maestros, precisamente, a ser maestro.

Por su parte, el proyecto investigativo busca trazar como apuesta pedagógica, pero también como escenario de encuentro y discusión, la pregunta por la pregunta, el debate por el cómo y para qué nos preguntamos y de qué manera se revierte ello en los acercamientos a la investigación.

Así, la articulación entre investigación y práctica se ha constituido en dimensión reflexiva que les permite a las estudiantes no solo comprender el mundo en el que le corresponde actuar, sino que también le ofrece criterios orientadores para interactuar con niños y niñas. Al respecto, los recientes trabajos de grado comienzan a cristalizar las inquietudes de conocimiento de los maestros en formación y a su vez, la interlocución con la práctica como escenario de complejidades. Ello se distancia, en su esencia, de asumir la investigación como una trayectoria lineal y cronológicamente controlada, pues, otros son los caminos recorridos con el grupo, caminos de ida y vuelta en los que la pregunta y reelaboración están presentes.

Por último, cabe señalar que la investigación aporta a la visibilización los momentos significativos en el transitar de la práctica durante los años 
que se plantearon en el estudio y a las acciones que se pueden realizar en la licenciatura, destacando el proceso permanente de diálogo entre los sujetos, los encuentros y desencuentros que hagan parte de la experiencia para llevarlos a un escenario de empoderamiento y de transformación social en relación con la cualificación de las prácticas en el programa, a fin de formar a los estudiantes como "personas críticas, reflexivas, garantes de los derechos y transformadores de conocimientos, poner en contexto saberes y adquirir competencias profesionales propios del pedagogo infantil a través de la investigación" (D4).

\section{Discusión}

La práctica se concibe como un eje transversal en la formación de maestros y como oportunidad para desaprender y reaprender, para que quien se está formando y quien forma se convenzan que "enseñar no es transferir conocimiento, sino crear las posibilidades de su producción o de su construcción" (Freire, 2006, p. 43).

La práctica va mucho más allá de ser un espacio para la confrontación teórica, la aplicación de aprendizajes, o reconocer contextos, es en cambio un escenario que potencia la comprensión respecto al quehacer pedagógico en educación infantil, lugar en el que el profesor "está llamado a reflexionar sobre: su proceso de planeación, la relación y el estilo pedagógico y el proceso de evaluación que lleva a cabo dentro de su quehacer" (Alvarado, 2013, p.100). En ese sentido, la mirada rigurosa respecto al problema de este campo exige posicionamientos críticos, argumentativos y reflexivos que atiendan a la necesidad de comprender el sentido de la formación de maestros para niños y niñas.

A propósito de ello, recientes estudios, como los desarrollados por Fandiño, et al (2018), insisten en la necesidad de comprender las creencias de los maestros de educación infantil como posibilidad para movilizar sus prácticas y potenciar la formación de los futuros licenciados,

Se identifican entre los docentes dos posturas discursivas disimiles, pero que confluyen en sus prácticas. Por una parte, los procesos de promoción intencional del desarrollo respetando las características y las particularidades de niños y niñas y por otra, la necesidad que les apremia de prepararlos ante las demandas que le serán exigidas en grados posteriores, principalmente los aprendizajes de contenidos formales sobre operaciones de aritmética básica y la enseñanza alfabética de la escritura y la lectura. (p. 101).

Es este uno de los fuertes debates que deben permear los programas de formación de maestros para la infancia, incluido por supuesto el de la Universidad Libre: el sentido de la educación infantil. Para ello, se requiere entender los procesos históricos que han configurado la misma, los desarrollos actuales y las gramáticas que sostienen la necesidad de procesos formativos rigurosos.

En este sentido, el acompañamiento a la práctica es un asunto que implica que los docentes que lideran este proceso, conozcan plenamente el ámbito en el que se inscribe su acción, a decir, las necesidades de formación y los contextos de interacción. Así, el asesor de práctica ha de disponer de una doble visión del medio escolar. En general, al poseer una experiencia docente este formador conoce la realidad del medio escolar y, al representar la institución universitaria, él conoce los objetivos y expectativas de la institución (...). Ellos ocupan así una posición privilegiada para estimular en los estudiantes en práctica la experimentación de nuevos enfoques pedagógicos. (Correa, 2011, p. 82) 
Al ser la práctica un espacio de confrontación, debate, incertidumbre, requiere que el docente problematice la cotidianidad, las realidades, reconozca potencialidades en las instituciones y contextos que acompaña. De allí que no puede pensarse la práctica como un mero ejercicio aplicativo o de observación, si no por el contrario, como la posibilidad de debate, reflexión, transformación para que en esta dinámica se posibilite la formación del maestro como sujeto social y político, a decir de Alvarado (2013) "se considera de vital importancia que los maestros en formación $y$ en ejercicio inicien y profundicen en procesos de reflexión permanente sobre su quehacer en el aula para generar praxis pedagógica” (p.100). Ello invita también a pensar en la necesidad de fortalecer producciones investigativas, publicaciones, participación del debate en distintos ámbitos y escenarios como espacios fundamentales para la consolidación y reconocimiento de experiencias pedagógicas de los maestros.

Finalmente, este ejercicio de sistematización posibilitó la escucha de los actores que dan vida a la experiencia de la práctica, encontrando lugares para comprender el proceso mismo y la necesidad de resignificar y fortalecer la formación de los maestros en educación infantil.

\section{Referencias}

Alvarado, C. V. (2013). Práctica pedagógica y gestión de aula, aspectos fundamentales en el quehacer docente. Revista Unimar, 31(2),99-113.

Bourdieu, P. (2007). El sentido práctico. Buenos Aires: Editorial siglo XXI.

Carvajal, A. (2004). Teoría y Práctica de la Sistematización de Experiencias. Cali: Universidad del Valle.

Castro, P., Chapman, R., Gili, S., Lull, V., Micó, R.,
Rihuete, C. y Sanahuja, M. E. (1996). Teoría de las prácticas sociales. Complutum extra, 6(2), 35-48.

Correa, M, E. (2011). La práctica docente: una oportunidad de desarrollo profesional. Perspectiva Educacional, 50(2), 77-95.

Díaz Quero, V. (2006). Formación docente, práctica pedagógica y saber pedagógico. Laurus, $12,88-103$.

Duhalde, M. (2007). La investigacion en la escuela un desafio para la formacion docente. Buenos Aires: Ediciones novedades educativas.

Escobar, L. y Ramírez, J. (2010). La sistematización de experiencias educativas y su lugar en la formación de maestras y maestros. Aletheia, 20(3), 98-107. Recuperado de http://aletheia.cinde.org.co/

Fandiño, G. M., Durán, S. M., Pulido, J. M., y Cruz, E. L. (2018). Creencias sobre educación inicial en colegios oficiales de Bogotá. Infancias imágenes, 17(1), 100-108.

Freire, P. (2006). Pedagogía de la autonomía: saberes necesarios para la práctica educativa. Siglo XXI Editores.

García, M. M. y Tirado, M. (2010). La sistematización de experiencias: producción de conocimientos desde y para la práctica. Revista Tendencias y Retos, (15), 97-107.

Ghiso, A. (1998). De la práctica singular al diálogo con lo plural, aproximaciones a otros tránsitos y sentidos de la sistematización en épocas de globalización. Recuperado de https:// goo.gl/QvUTA8

Jara, O. (2001). Dilemas y desafíos de la sistematización de experiencias. Presentación realizada en el mes de abril 2001, Cochabamba, Bolivia, en el Seminario ASOCAM: Agricultura Sostenible Campesina de Montaña, organizado por Intercooperation.

Jara, O. (2012). Sistematización de experiencias, investigación y evaluación: aproximaciones 
desde tres ángulos. $\mathrm{F}(\mathrm{x})=$ Educación Global Research, 1, 56-70. Recuperado de https:// goo.gl/6EgziY

Jara, O. (2014). La Sistematización De Experiencias Práctica Y Teoría Para Otros Mundos Posibles. Lima: Centro de Estudios y $\mathrm{Pu}$ blicaciones Alforja. Recuperado de https:// goo.gl/wHVxUZ

Larrosa, J. (2014). La experiencia de la lectura: estudio sobre literatura y formación. México: Fondo de Cultura Económica. Recuperado de https://goo.gl/EjaoHy

Messina, G., y Osorio, J. (2016). Sistematizar como ejercicio eco-reflexivo: La fuerza del relato en los procesos de sistematización de experiencias educativas. Revista e-Curriculum, 14(2).Recuperado https://goo.gl/CALNj2

Runge, A. (2002). Una epistemología histórica de la pedagogía: El trabajo de Olga Lucía Zuluaga. Revista de Pedagogia, 23(68), 361385. Recuperado de https://goo.gl/w7nM8z

Runge, A. y Muñoz, D. (2012). Pedagogía y praxis (práctica) educativa o educación. De nuevo: una diferencia necesaria. Revista Latinoamericana de Estudios Educativos. 8(2), 75-96.
Runge Peña, A. y Muñoz Gaviria, D. (2012). Pedagogía y Praxis (práctica) educativa o educación. De nuevo: una diferencia necesaria. Revista Latinoamericana de Estudios Educativos (Colombia), 8(2), 75-96. Recuperado de https://goo.gl/p3FvyX

Suárez, D. (2011). La documentación narrativa de experiencias pedagógicas como estrategia de investigación-formación-acción. Revista del Instituto de investigaciones en ciencias de la educación (30), 17- 30. Recuperado de file:///C:/Users/editorial/Downloads/142331-1-SM.pdf

Torres, C. (1999). La sistematización de experiencias educativas: reflexiones sobre una práctica recientes búsquedas. Pedagogía y Saberes (13). Recuperado de http://revistas. pedagogica.edu.co/index.php/PYS/article/ view/5983

Universidad Libre - Documento Condiciones iniciales para el proceso de acreditación. (2015). Licenciatura en Pedagogía Infantil. Facultad de Ciencias de la Educación.

Universidad Libre - Documento de Registro Calificado. (2005). Facultad de Ciencias de la Educación. Licenciatura en Pedagogía Infantil. 